\title{
Object Recognition and Location Memory in Monkeys with Excitotoxic Lesions of the Amygdala and Hippocampus
}

\author{
Elisabeth A. Murray and Mortimer Mishkin \\ Laboratory of Neuropsychology, National Institute of Mental Health, Bethesda, Maryland 20892
}

Earlier work indicated that combined but not separate removal of the amygdala and hippocampus, together with the cortex underlying these structures, leads to a severe impairment in visual recognition. More recent work, however, has shown that removal of the rhinal cortex, a region subjacent to the amygdala and rostral hippocampus, yields nearly the same impairment as the original removal. This raises the possibility that the earlier results were attributable to combined damage to the rostral and caudal portions of the rhinal cortex rather than to the combined amygdala and hippocampal removal. To test this possibility, we trained rhesus monkeys on delayed nonmatching-to-sample, a measure of visual recognition, gave them selective lesions of the amygdala and hippocampus made with the excitotoxin ibotenic acid, and then assessed their recognition abilities by using increasingly longer delays and list lengths, including delays as long as $40 \mathrm{~min}$. Postoperatively, monkeys with the combined amygdala and hippocampal lesions performed as well as intact controls at every stage of testing. The same monkeys also were unimpaired relative to controls on an analogous test of spatial memory, delayed nonmatching-tolocation. It is unlikely that unintended sparing of target structures can account for the lack of impairment; there was a significant positive correlation between the percentage of damage to the hippocampus and scores on portions of the recognition performance test, suggesting that, paradoxically, the greater the hippocampal damage, the better the recognition. The results show that, within the medial temporal lobe, the rhinal cortex is both necessary and sufficient for visual recognition.

Key words: amygdala; hippocampus; limbic system; ibotenic acid; visual memory; delayed nonmatching-to-sample; spatial memory; recognition memory
Earlier ablation studies (Mishkin, 1978; Zola-Morgan et al., 1982; Murray and Mishkin, 1984; Saunders et al., 1984) had led to the conclusion that combined damage to the amygdala and hippocampus produces a severe impairment in visual recognition. However, more recent studies have indicated that combined damage to the perirhinal and parahippocampal cortical regions located ventral to the amygdala and hippocampus results in substantial deficits in stimulus recognition (Zola-Morgan et al., 1989; Suzuki et al., 1993). Indeed, lesions limited to the rhinal cortex (i.e., entorhinal and perirhinal cortex; see Fig. 1) also yield a pronounced recognition impairment (Meunier et al., 1993; Eacott et al., 1994), one nearly as severe as that observed after the original amygdala and hippocampal removals, thereby raising doubts about the initial conclusion. There are two possible interpretations of these several findings. First, the behavioral impairment originally observed after the combined amygdala and hippocampal removals could be attributable entirely to the concomitant rhinal cortical damage. If so, then selective lesions of the amygdala and hippocampus that spare the rhinal cortex should yield no impairment in visual recognition. Alternatively, the effects of rhinal cortex lesions might reflect a visual corticolimbic disconnection, inasmuch as the amygdala and hippocampus receive

Received March 26, 1998; revised May 21, 1998; accepted June 3, 1998.

This work was supported by the Intramural Research Program of the National Institute of Mental Health. We thank the staff of the In Vivo Nuclear Magnetic Resonance Research Center for performing magnetic resonance imaging scans of the monkeys; V. J. O'Boyle, Jr., M. Hall, and M. Dow for testing the monkeys and assisting in surgery; and T. Fobbs and M. Lovorn for histological processing of the tissue. W. Hadfield and J. Sewell provided additional valuable technical support.

Correspondence should be addressed to Dr. Elisabeth A. Murray, Laboratory of Neuropsychology, National Institute of Mental Health, Building 49, Room 1B80, 49 Convent Drive, Bethesda, MD 20892-4415.

Copyright (C) 1998 Society for Neuroscience $\quad 0270-6474 / 98 / 186568-15 \$ 05.00 / 0$ their major visual input via the rhinal cortex (Van Hoesen and Pandya, 1975; Herzog and Van Hoesen, 1976; Aggleton et al., 1980; Van Hoesen, 1981; Saunders and Rosene, 1988; Witter et al., 1989; Suzuki and Amaral, 1990; Stefanacci et al., 1996). Thus both the rhinal cortex, on the one hand, and the amygdala plus hippocampus, on the other, might serve as serial processing stages in a circuit mediating visual recognition, much as originally envisaged (Mishkin, 1982). If this were the case, then selective lesions of the amygdala and hippocampus would be expected to reproduce the severe recognition deficit observed originally (Mishkin, 1978). These contrasting possibilities were tested in Experiment 1. Monkeys were trained on a standard test of visual recognition, delayed nonmatching-to-sample (DNMS) with trialunique objects, given selective lesions of the amygdala and hippocampus made with the excitotoxin ibotenic acid, and then assessed for their recognition ability with varying delays and list lengths. The surgical procedure was intended to produce complete cell loss in the amygdala and hippocampus but to spare the underlying rhinal cortex as well as any fibers passing nearby or through these medial temporal lobe structures.

While the present study was in progress, Alvarez et al. (1995) published a report showing that monkeys with radiofrequency lesions of the hippocampus, although unimpaired on DNMS with relatively short delays (up to $1 \mathrm{~min}$ ), were impaired significantly when delays of 10 and 40 min intervened between sample and choice. Because the longest delay intervals in our first assessment were below $5 \mathrm{~min}$, we retested a subset of our monkeys with delays that included the longer intervals used by Alvarez et al. (1995). For this second assessment the test was designed to determine the precise delay at which visual recognition might start to be dependent on the deep temporal lobe structures. 
In Experiment 2 we tested the monkeys on a delayed nonmatching-to-location task to assess their spatial memory ability in a manner analogous to that used to assess their object recognition memory.

Portions of this work have appeared earlier in abstract form (O’Boyle et al., 1993; Murray and Mishkin, 1996).

\section{MATERIALS AND METHODS}

\section{Experiment 1}

Subjects. The subjects were 11 experimentally naive male rhesus monkeys (Macaca mulatta) weighing 3.6-6.5 kg at the beginning of the study. The monkeys were housed individually in rooms with automatically regulated lighting (12 hr light/12 hr dark cycle). They were fed a diet of monkey chow (PMI Feeds, St. Louis, MO) supplemented with fruit; water was always available.

Apparatus and materials. Training was conducted in a modified Wisconsin General Testing Apparatus (WGTA) inside a darkened room. Sound masking was provided by a white-noise generator. The test tray contained a row of three food wells spaced $18 \mathrm{~cm}$ apart (center to center) and aligned $16 \mathrm{~cm}$ in front of the animal's cage. A single banana-flavored pellet $(300 \mathrm{mg}$, P. J. Noyes, Lancaster, $\mathrm{NH}$ ) or one-half of a peanut, concealed in one of the wells, served as the reward. Gray cardboard plaques, $7.5 \mathrm{~cm}$ on a side, and three junk objects reserved for the purpose were used in preliminary training. Test material consisted of over 1120 additional objects that varied widely in size, shape, color, and texture. A particular object reappeared in testing only approximately once per month.

Preoperative training. The monkeys were trained first by successive approximation to displace a cardboard plaque to obtain a food reward hidden in the well beneath it and then to displace the three pretraining objects, which were presented singly over one of the three wells. Then the monkeys were given 20 pseudotrials to familiarize them with the structure of the task. For this purpose, one of the three pretraining objects was presented as the "sample" over the baited central well; $10 \mathrm{sec}$ later the two others were presented over the lateral wells, both or neither of which were baited, in pseudorandom order. The monkey was allowed to displace only one of them. The pseudotrials were separated by $30 \mathrm{sec}$ intervals. During the $10 \mathrm{sec}$ delay intervals and the $30 \mathrm{sec}$ intertrial intervals, an opaque screen separated the monkey from the test tray. During stimulus presentations, when the opaque screen was raised, a one-way vision screen blocked the monkey's view of the experimenter. This preliminary training was completed in 3-10 d.

The formal trials were like the pseudotrials except that two new objects were used on every trial and the sample object was presented again on the choice test but was not baited, whereas the novel object was always baited. The left-right position of the novel object on the choice test followed a balanced pseudorandom order, and there was no correction for errors. Monkeys were trained at a rate of 20 trials per day, $5 \mathrm{~d}$ per week, to a criterion of 90 correct responses in 100 consecutive trials over five consecutive sessions.

After learning the basic DNMS rule, the monkeys were assigned to two groups matched on the basis of their preoperative learning scores. One group $(n=4)$ remained as normal controls, whereas the other $(n=7)$ received bilateral excitotoxic lesions of the amygdala and hippocampus.

Surgery. Before surgery each monkey was anesthetized with a mixture $(10: 1, \mathrm{v} / \mathrm{v} ; 0.1 \mathrm{ml} / \mathrm{kg}$, i.m.) of ketamine hydrochloride $(100 \mathrm{mg} / \mathrm{ml})$ and xylazine $(20 \mathrm{mg} / \mathrm{ml})$, placed in a specially constructed nonferrous stereotaxic frame, and given a brain scan using the magnetic resonance imaging (MRI) technique. The MRI scans were used to obtain measurements of the amygdala and hippocampus relative to the midline and the interaural plane, marked by the earbars, which also were visible on the scan (Saunders et al., 1990). From these measurements we determined stereotaxic coordinates for the injection sites. Those for the amygdala were separated from each other by a distance of $\sim 2 \mathrm{~mm}$ in each plane, and the number of sites $(18-26)$ was tailored to the individual subject. The injection sites for the hippocampus included one in the uncus and five more in the body of the hippocampus, each site separated from the other by $3 \mathrm{~mm}$ in the anteroposterior plane and each aimed at the center of the structure as viewed in the coronal plane. Based on empirical findings, the selection of sites was intended to allow diffusion of the excitotoxin ibotenic acid (Regis Chemical, Morton Grove, IL, or Sigma, St. Louis, $\mathrm{MO}$ ) throughout the entire amygdaloid complex and hippocampus (i.e., Ammon's horn and dentate gyrus). Figure 1 illustrates the extent of the intended lesion.
For the surgery each monkey was reanesthetized with ketamine hydrochloride $(10 \mathrm{mg} / \mathrm{kg}, \mathrm{i} . \mathrm{m}$.), followed by isoflurane (1-2\%, to effect), and then treated with atropine sulfate $(0.04 \mathrm{mg} / \mathrm{kg}$, i.m. $)$ to reduce secretions. Then the monkey was replaced in the stereotaxic frame, and heart rate, respiration rate, body temperature, expired $\mathrm{CO}_{2}$ level, blood oxygen level, and blood pressure were monitored throughout the procedure, which was performed aseptically.

A large bone flap was turned over the dorsal aspect of the cranium. The flap extended $\sim 25 \mathrm{~mm}$ rostral to bregma, $20 \mathrm{~mm}$ caudal to bregma, and $20-25 \mathrm{~mm}$ to each side of the midline. Lesions were made according to the method described by Murray et al. (1996) and Malkova et al. (1997). Small slits were cut in the dura to allow the needle of a $10 \mu$ l Hamilton syringe, held in a Kopf electrode manipulator (David Kopf Instruments, Tujunga, CA), to be lowered to the proper coordinates. In the amygdala, $1.0 \mu \mathrm{l}$ of ibotenic acid $(10-15 \mathrm{mg} / \mathrm{ml})$ was injected at each site. In the hippocampus, $1.8 \mu \mathrm{l}$ of ibotenic acid was injected at each site in the first three cases (cases AH1-AH3) and $2.0 \mu \mathrm{l}$ at each site in the remaining cases (cases AH4-AH7). To minimize tissue damage and still allow diffusion of the ibotenic acid, we made all injections at a rate of 0.2 $\mu \mathrm{l} / \mathrm{min}$. Because a large and potentially lethal amount of ibotenate would be required to complete the lesions in both hemispheres in a single stage of surgery, the monkeys received the amygdala plus hippocampal lesions in two stages, left hemisphere followed by right, separated by a minimum of 2 weeks.

When the injections at each stage of surgery were completed, the bone flap was replaced, the wound was sutured in anatomical layers, and the monkeys typically received mannitol $(30 \%, 30 \mathrm{ml}$, i.v., over $30 \mathrm{~min})$ to prevent edema and thereby promote recovery from surgery. All monkeys received dexamethasone sodium phosphate $(0.4 \mathrm{mg} / \mathrm{kg})$ and Di-Trim $(0.1 \mathrm{ml} / \mathrm{kg}, 24 \%$ solution, i.m.) on the day before surgery and daily for 1 week after surgery to reduce swelling and to prevent infection, respectively. Monkeys also received acetaminophen $(40 \mathrm{mg})$ or Banamine (1.0 $\mathrm{mg} / \mathrm{kg}$ ) for $3 \mathrm{~d}$ after surgery for relief of pain.

Histology. At the end of the experiment the monkeys in the operated group were given a lethal dose of barbiturates and perfused intracardially with a saline solution $(0.9 \%)$, followed by $10 \%$ buffered formalin. The brains were removed, photographed, frozen, and cut at $50 \mu \mathrm{m}$ in the coronal plane on a freezing microtome. Every fifth section was mounted on a gelatin-coated slide, defatted, stained with thionin, and coverslipped.

Regions of cell loss and gliosis, determined with a stereoscopic microscope, were plotted on standard sections of a rhesus monkey brain, and the volume of the lesion was calculated with a digitizer (see Meunier et al., 1993). The results are shown in Table 1 and Figures $2-8$. The damage averaged $88 \%$ (range, $81-100 \%$ ) of the total extent of the amygdala and $73 \%$ (range, 55-98\%) of the hippocampus (i.e., Ammon's horn plus dentate gyrus). As these results indicate, the ibotenate injections were not consistently effective, despite the fact that the solution was prepared in the same way each time and that the patency of the syringe needle was verified before each penetration. The explanation for the inconsistency is therefore still unclear. However, the MRI-based stereotaxic surgical approach was quite accurate, as evidenced by the small amount of damage that occurred outside the targeted structures. In particular, damage to the entorhinal cortex averaged $24 \%$ (range, $0-70 \%$ ), and to the perirhinal cortex it averaged only $4 \%$ (range, $0-20 \%$ ). Also, the tissue was typically free of holes and vacuoles, suggesting that there was little or no damage either to white matter or to fibers coursing through the amygdala or hippocampus.

Postoperative testing. At $\sim 9$ weeks after the completion of preoperative training (range for control monkeys, 3-12 weeks; for operated monkeys, 6-16 weeks) the monkeys were retrained on the basic DNMS task to the same criterion as before. All monkeys then were given a performance test in which, first, the delay between sample presentation and choice test was lengthened in stages from the initial delay of $10 \mathrm{sec}$ to 30,60 , and 120 sec, and then the list of sample objects to be remembered was increased in steps from the original single object to 3, 5, and, finally, 10 objects. In the list-length tests, the sample objects were presented one at a time at 20 sec intervals, and then each sample was paired successively with a different novel object, also at $20 \mathrm{sec}$ intervals. Consequently, the minimum retention interval for each trial was $20 \mathrm{sec}$ multiplied by the length of the list. For each delay condition the monkeys received five consecutive daily sessions of 20 trials each, whereas for each list-length condition they received five consecutive daily sessions of 30 trials each.

After they had completed the performance test with delays and lists, the stimulus recognition abilities of all of the control monkeys and a 


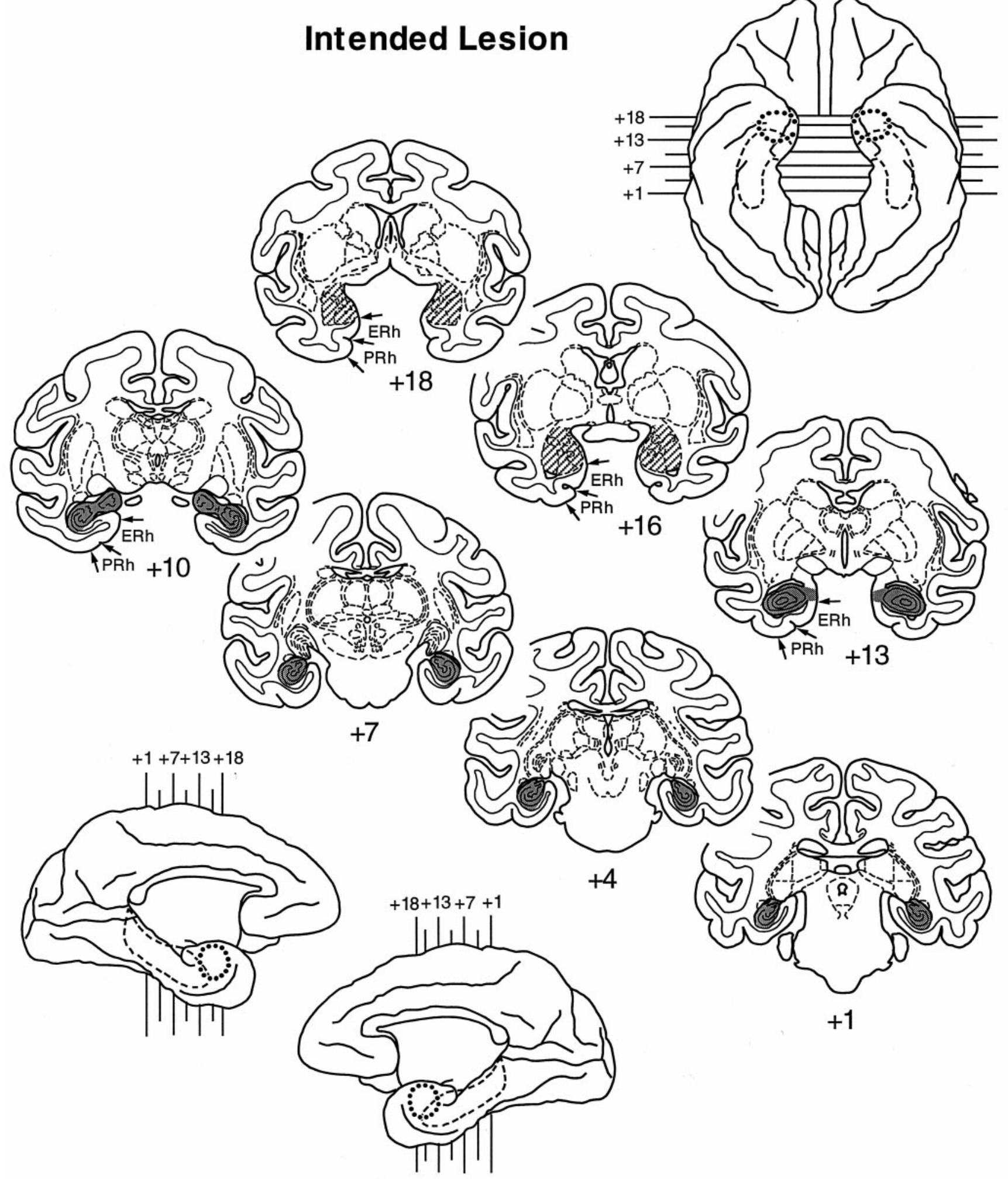

Figure 1. Shaded regions indicate the location and extent of the intended lesion of the amygdala (oblique hatching) and hippocampus ( gray) on standard coronal sections. Ventral (top right) and medial (bottom left) views of a standard rhesus monkey brain show the locations of these deep temporal lobe structures: amygdala, dotted line; hippocampus, dashed line. In addition, small arrows mark the boundaries of the entorhinal (ERh) and perirhinal (PRh) cortex, regions we intended to spare, on the coronal sections only (left hemisphere; $+18,+16,+13,+10$ ). The numerals indicate the distance in millimeters from the interaural plane. 


\begin{tabular}{|c|c|c|c|c|c|c|c|c|c|c|c|c|c|c|c|}
\hline \multirow[b]{2}{*}{ Case } & \multicolumn{3}{|c|}{ Amygdala } & \multicolumn{3}{|c|}{ Hippocampus } & \multicolumn{3}{|c|}{ Subiculum } & \multicolumn{3}{|l|}{ PRh } & \multicolumn{3}{|c|}{ ERh } \\
\hline & $\mathrm{L} \%$ & $\mathrm{R} \%$ & $\mathbf{M}$ & $\mathrm{L} \%$ & $\mathrm{R} \%$ & M & $\mathrm{L} \%$ & $\mathrm{R} \%$ & $\mathbf{M}$ & $\mathrm{L} \%$ & $\mathrm{R} \%$ & $\mathbf{M}$ & $\mathrm{L} \%$ & $\mathrm{R} \%$ & $\mathbf{M}$ \\
\hline AH1 & 95 & 79 & 87 & 90 & 62 & 76 & 51 & 29 & 40 & 0 & 2 & 1 & 12 & 8 & 10 \\
\hline $\mathrm{AH} 2$ & 68 & 94 & 81 & 46 & 92 & 69 & 46 & 62 & 54 & 0 & 11 & 6 & 20 & 56 & 38 \\
\hline $\mathrm{AH} 3$ & 100 & 98 & 99 & 98 & 98 & 98 & 81 & 76 & 79 & 19 & 21 & 20 & 81 & 58 & 70 \\
\hline $\mathrm{AH} 4$ & 99 & 63 & 81 & 92 & 89 & 90 & 56 & 29 & 42 & 1 & 0 & 0 & 46 & 21 & 34 \\
\hline AH5 & 69 & 93 & 81 & 75 & 59 & 67 & 32 & 13 & 22 & 0 & 0 & 0 & 0 & 0 & 0 \\
\hline AH6 & 100 & 100 & 100 & 68 & 48 & 58 & 27 & 13 & 20 & 0 & 2 & 1 & 12 & 9 & 10 \\
\hline AH7 & 99 & 68 & 84 & 55 & 55 & 55 & 15 & 42 & 29 & 1 & 0 & 1 & 10 & 6 & 8 \\
\hline Mean & 90 & 85 & 88 & 75 & 72 & 73 & 44 & 38 & 41 & 3 & 5 & 4 & 26 & 23 & 24 \\
\hline
\end{tabular}

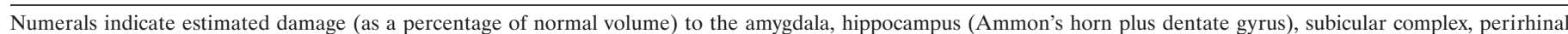

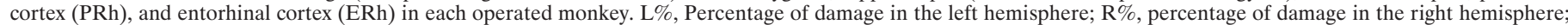
$\mathrm{M}$, mean of $\mathrm{L} \%$ and $\mathrm{R} \%$; AH1-AH7, monkeys with bilateral excitotoxic lesions of the amygdala and hippocampus.
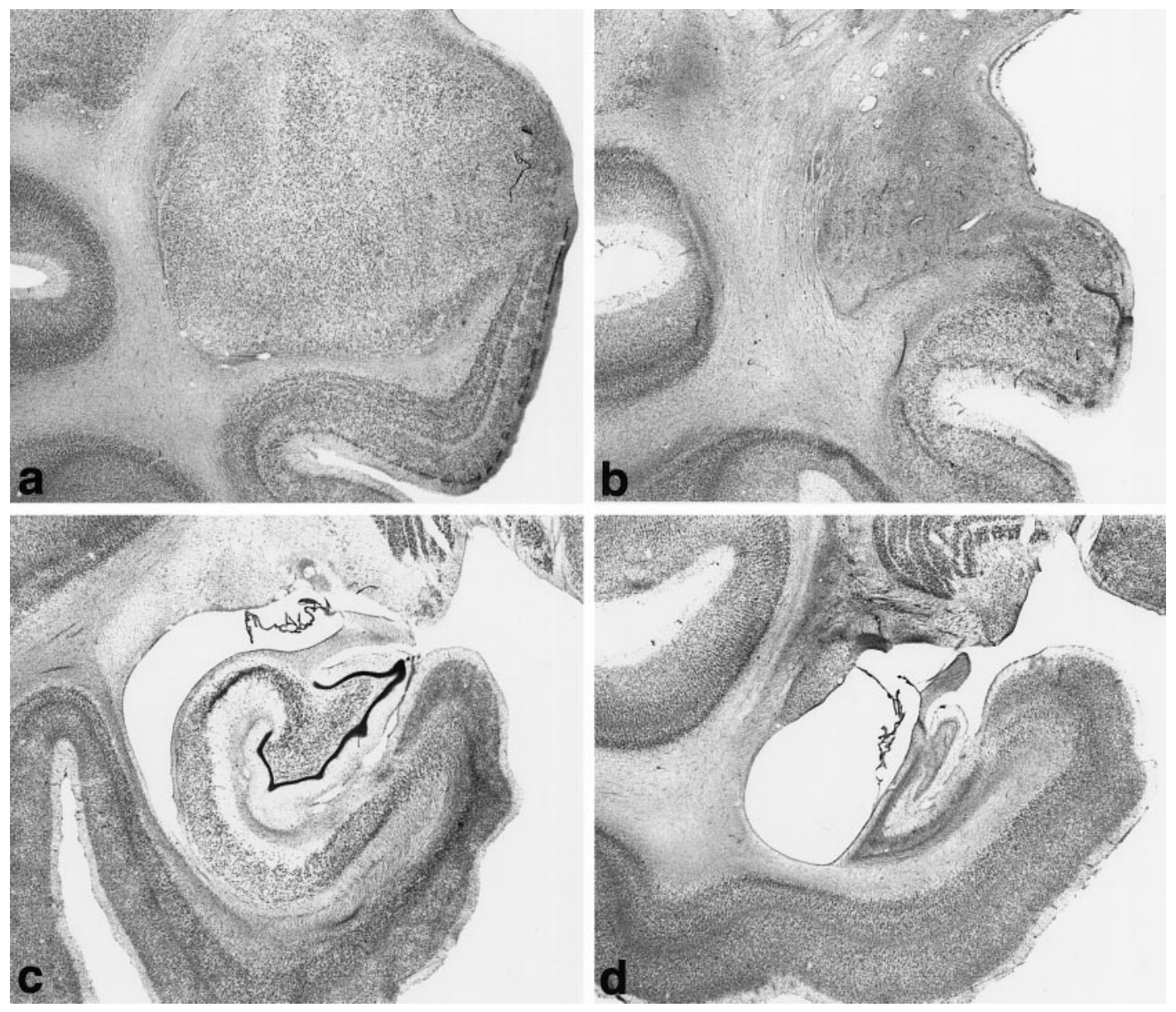

Figure 2. Photomicrographs of Nissl-stained coronal sections showing the region of the medial temporal lobe in intact monkeys $(a, c)$ and monkeys with excitotoxic lesions $(b, d) . a$, Intact amygdala and portions of underlying rhinal cortex. $b$, Excitotoxic amygdala lesion in monkey AH7, photographed at the same magnification as $a$. Note the massive neuronal cell loss, gliosis, and atrophy in the amygdala, with relative preservation of neurons in the surrounding structures. $c$, Intact hippocampus, subicular complex, and underlying parahippocampal cortex. $d$, Excitotoxic hippocampal lesion in monkey AH1, photographed at the same magnification as $c$. Note the massive neuronal cell loss, gliosis, and atrophy in the hippocampus, partial cell loss in the subicular complex, and relative preservation of the surrounding regions.

subset of operated monkeys (AH4-AH7) were examined with still longer lists and delays. First, they received DNMS with a list length of 20 objects (LL20) for 5 d consecutively. The procedure was the same as before except that the daily sessions consisted of only 20 trials instead of 30. Because one-half of the animals in each group (N3, N4, AH6, AH7) obtained unexpectedly low scores on LL20, they were given supplemental training on lists of 3,5 , and 10 objects and then retested on LL20; only these retest scores are included in the LL20 analysis. For the final stage all the monkeys received DNMS with a list length of 40 (LL40) objects but with reverse-order testing. That is, after the 40 samples were presented for familiarization, they were presented on the choice test in reverse order, such that the last sample in the list appeared on the first choice test and the first sample appeared on the last choice test. All stimulus presentations in the 

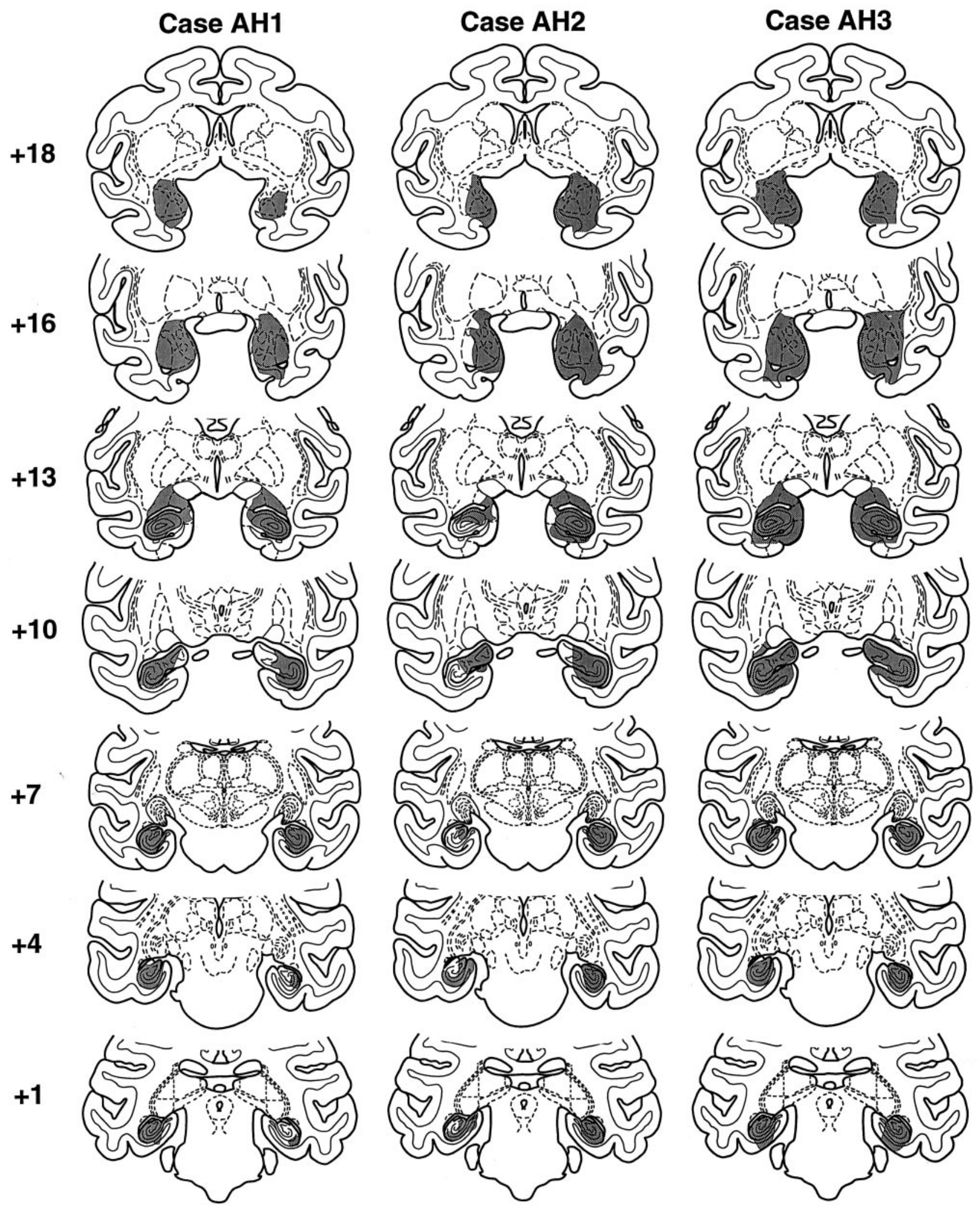

Figure 3. Shaded regions on standard coronal sections indicate the location and extent of the excitotoxic amygdala and hippocampal lesions in monkeys AH1-AH3. Numerals indicate the distance in millimeters from the interaural plane. 

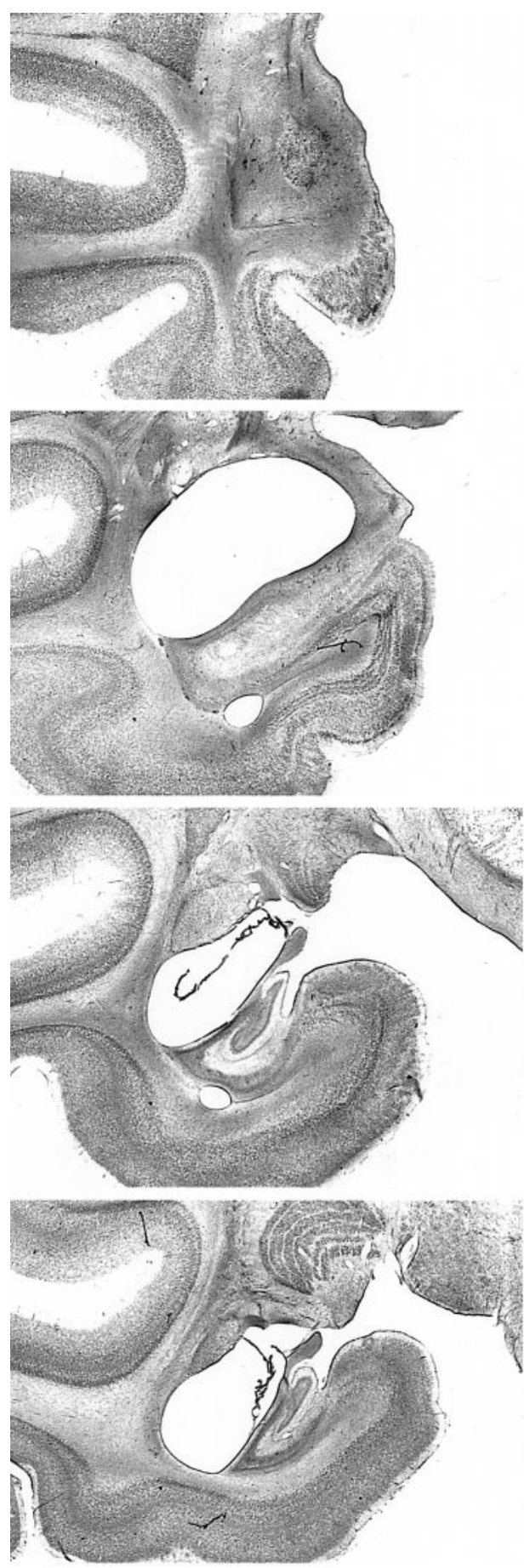
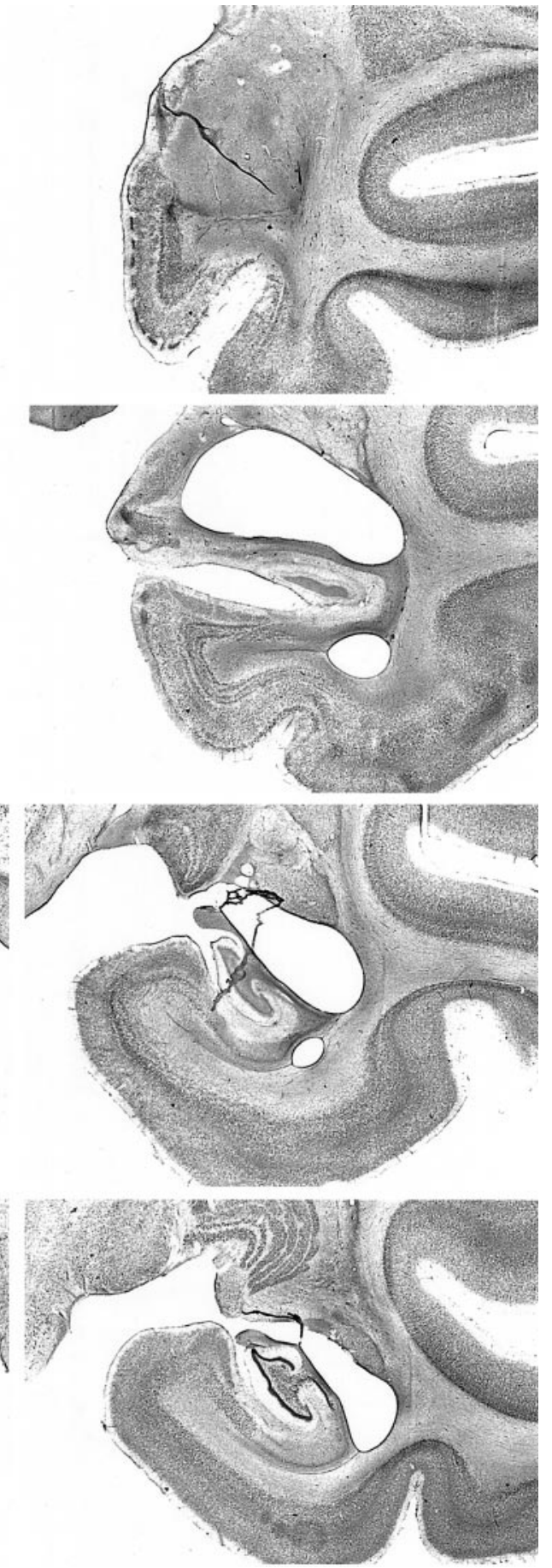

Figure 4. Photomicrographs of Nisslstained coronal sections from monkey AH1. From top to bottom, the sections are approximately $+17,+13,+8$, and $+4 \mathrm{~mm}$ from the interaural plane, respectively. Compare with Figures 2 and 3.

damage to the hippocampus, the parahippocampal cortex, or their combination, on the basis of an earlier report of impairment on a similar task in adult monkeys with neonatal removals of this hippocampal region (Mahut and Moss, 1986).

Subjects. The subjects were the same monkeys that participated in the final stage of Experiment 1, except for one of the unoperated control monkeys (NC2) who had died of bloat after the completion of Experiment 1 .

Apparatus and materials. The monkeys were tested in the same WGTA as in Experiment 1, but with a different test tray. This tray, measuring 70 $\mathrm{cm}$ wide and $25 \mathrm{~cm}$ deep, had 10 food wells, each $4 \mathrm{~cm}$ in diameter, arranged in horizontal rows of three, four, and three. The rows were $9 \mathrm{~cm}$ apart, and the wells within a row were $16 \mathrm{~cm}$ apart, center to center. The stimuli were gray cardboard squares, $\sim 5 \mathrm{~cm}$ on a side, and these were renewed frequently. recently found a pronounced deficit on it in adult monkeys with neonatal removals of the medial temporal lobe. The deficit was attributed to supposition is based on a long history of research in both rodents an primates implicating the hippocampus in a wide variety of spatial mem ory functions (for review, see O'Keefe and Nadel, 1978; Eichenbaum al., 1994). The task selected was delayed nonmatching-to-location both al., 1994). The task selected was delayed nonmatching-to-location both 

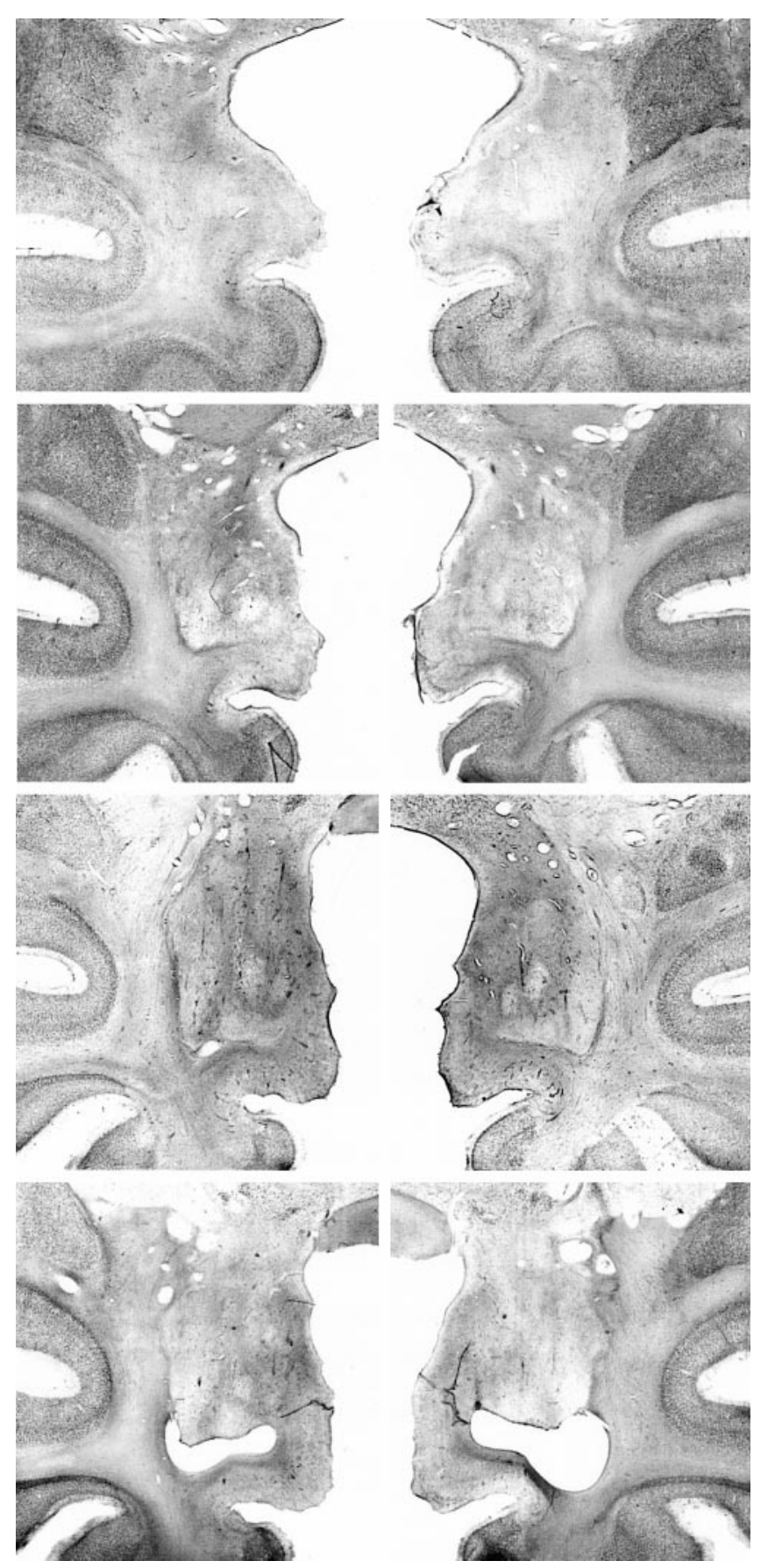

Testing procedure. The test procedure was the same as that used by Malkova et al. (1995). As in DNMS with objects, each trial was composed of two parts: sample presentation followed by choice test. On the sample presentation one of the wells was covered with a gray plaque, which the monkey displaced to obtain a food reward. On the choice test, $10 \mathrm{sec}$ later, two wells were covered by identical gray plaques, one on the sample location and the other on a randomly selected alternative. The monkey could obtain another food reward by displacing the plaque in the new location. Daily sessions consisted of 20 trials, separated by $30 \mathrm{sec}$ intervals, and criterion was set at 90 correct responses in 100 trials over five consecutive sessions. After attaining criterion, the animals were given a performance test with delays of $10,30,60$, and $120 \mathrm{sec}$ for five trials each, mixed within each session. The test was given for $20 \mathrm{~d}$, yielding 100 trials per delay. Finally, the monkeys were tested with a list length of two locations to remember (LL2). For this procedure two consecutive sample presentations were followed by two consecutive choice tests. That is, the monkey saw a single gray plaque overlying a well, which it uncovered for
Figure 5. Photomicrographs of Nissl-stained coronal sections from monkey AH3. Left, top to bottom, The sections through the amygdala are approximately $+18.5,+17,+16$, and $+14.5 \mathrm{~mm}$ from the interaural plane, respectively. Right, top to bottom, The sections through the hippocampus are approximately $+11,+8,+6$, and $+4 \mathrm{~mm}$ from the interaural plane, respectively. Compare with Figures 2 and 3. Figure continues.

the food reward, and then, $10 \mathrm{sec}$ later, a single plaque overlying another well, which it also uncovered for a reward. After an additional $10 \mathrm{sec}$ the monkey was given the choice test for the first sample and, $10 \mathrm{sec}$ later, the choice test for the second sample. Training proceeded at the rate of 20 trials per day, for a total of $20 \mathrm{~d}$.

\section{RESULTS}

\section{Experiment 1}

As shown in Table 2, the two groups were well matched for rate of preoperative learning. Both attained criterion, on average, within six to seven daily sessions (Mann-Whitney $U$ tests, trials: $U=12.0, p=0.70$; errors: $U=13, p=0.85$ ). Further, there was no effect of the lesions on postoperative relearning, inasmuch as six of the seven operated monkeys, like 


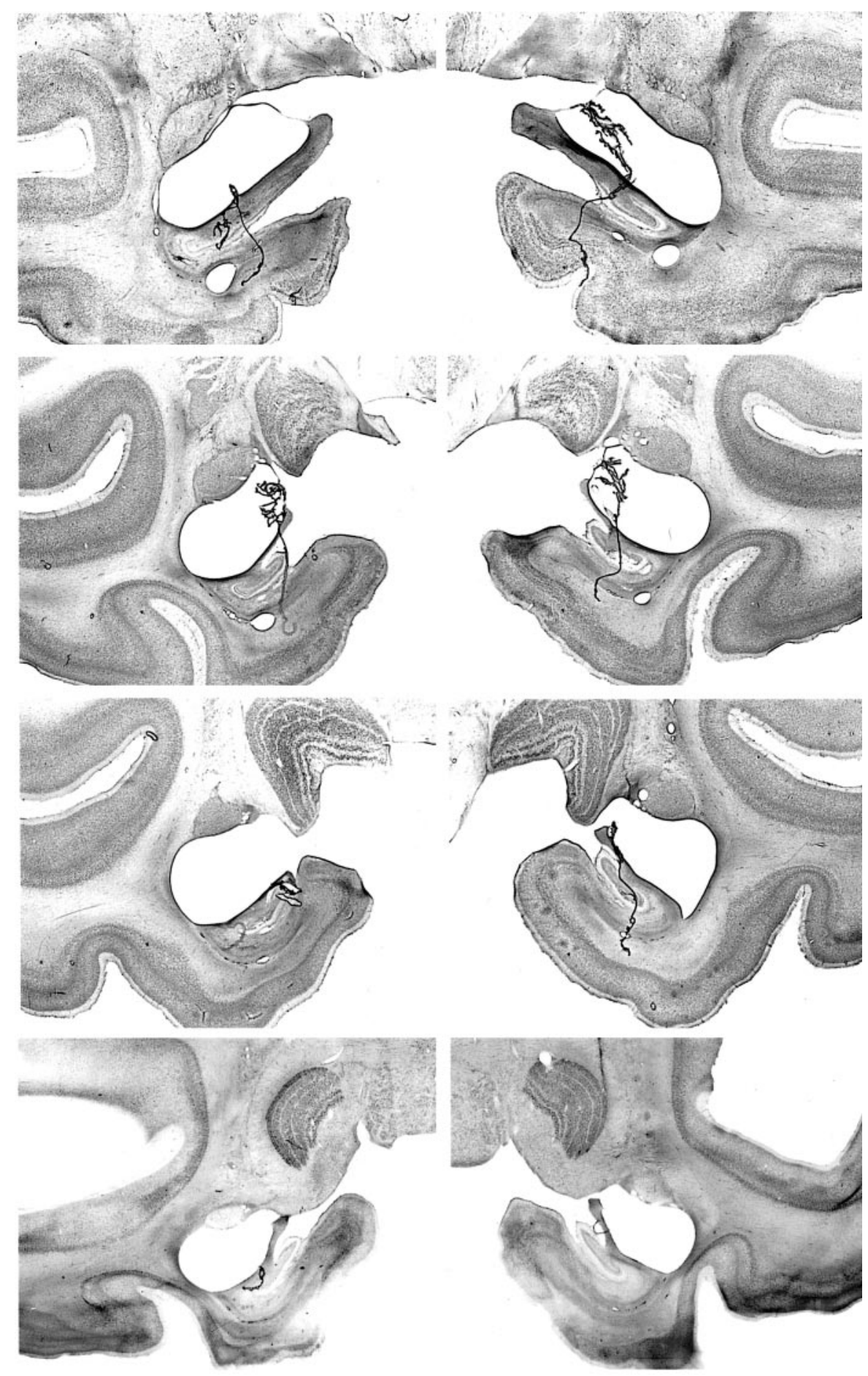

Figure 5 continued.

three of the four controls, showed perfect postoperative retention of the DNMS rule (Mann-Whitney $U$ tests, $U=12.5, p=$ 0.67 , for both trials and errors).

The mean scores on the subsequent performance test were analyzed by a 2 (group) $\times 7$ (condition, i.e., four delays and three list lengths) repeated measures ANOVA. There was no difference between the two groups $\left[F_{(1,9)}=0.051, p=0.83\right]$, and, although there was a main effect of condition $\left[F_{(6,54)}=17.26, p<0.001\right]$, there was no interaction between group and condition $\left[F_{(6,54)}=\right.$ $0.43, p=0.71]$. Thus, although the scores of all of the monkeys declined with increasing memory demands (particularly, increasing list lengths; see Fig. 9), those with $\mathrm{AH}$ lesions were not affected more than the controls, nor did the two groups differ on LL20 (normal control: mean $=75 \%$, range $=70-79 \%$; $\mathrm{AH}$ : mean $=74.5 \%$, range $=61-85 \%)$, on which both groups performed slightly below their levels on LL10 (see Table 2). 

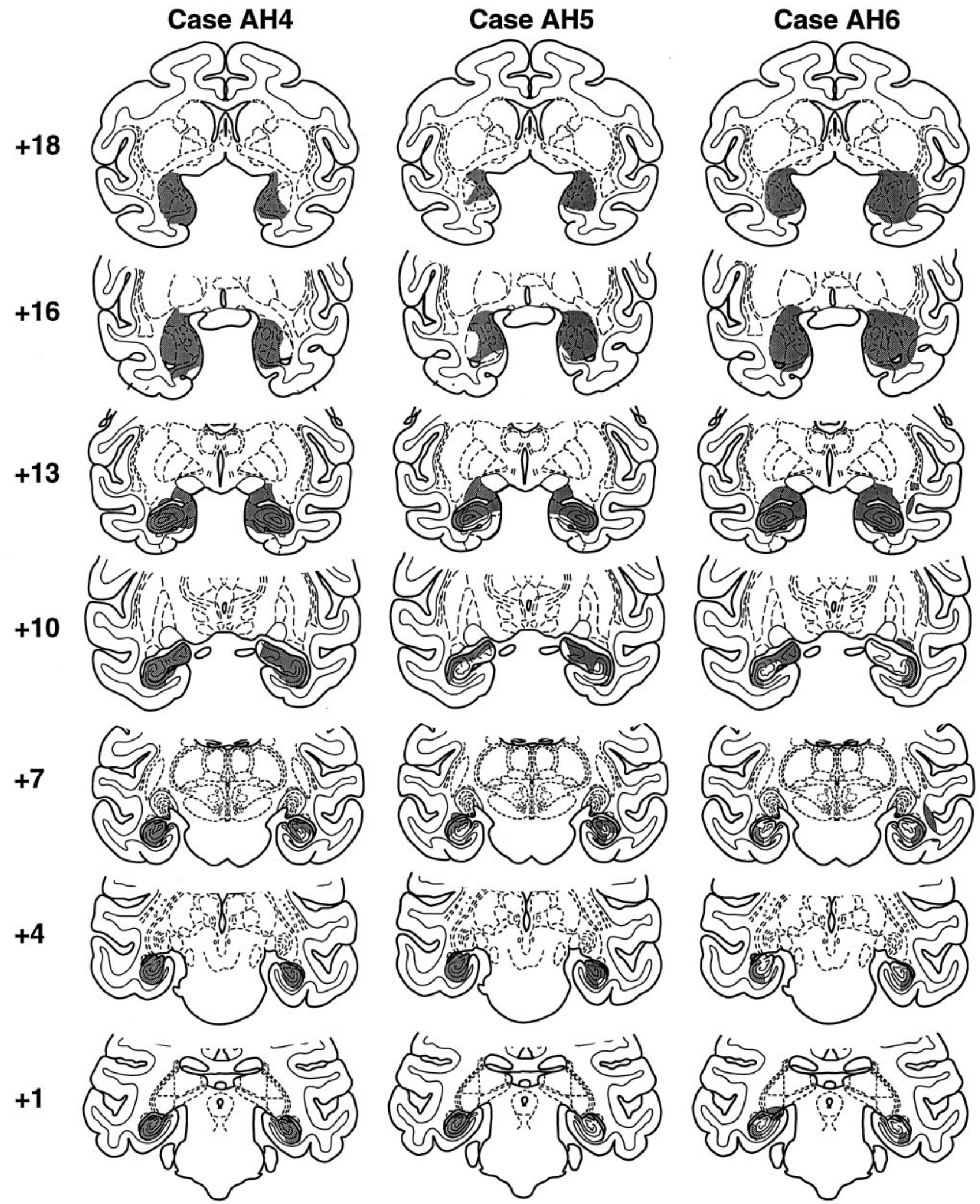

Figure 6. Shaded regions on standard coronal sections indicate the location and extent of the excitotoxic amygdala and hippocampal lesions in monkeys AH4-AH6. Numerals indicate the distance in millimeters from the interaural plane. 

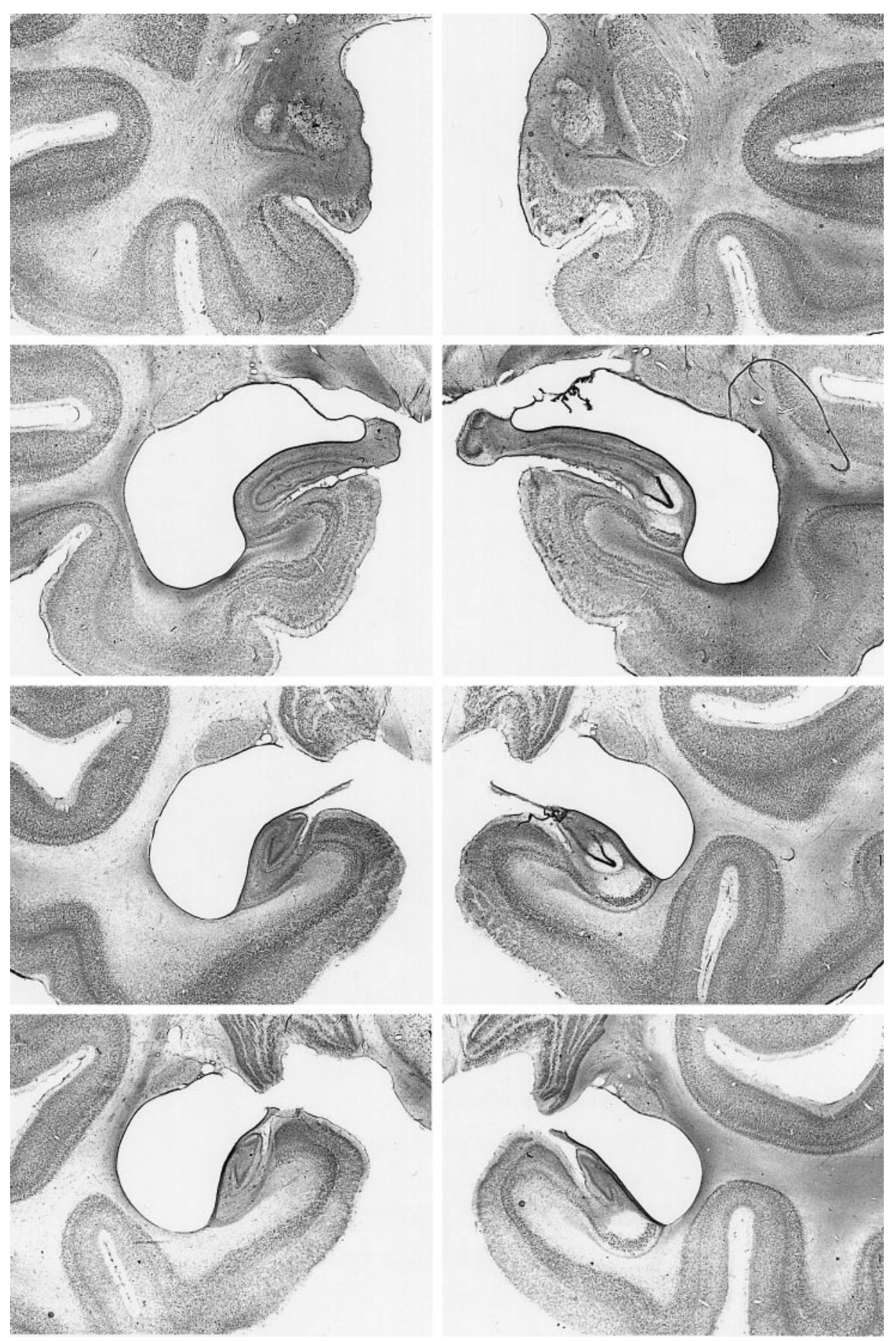

Figure 7. Photomicrographs of Nisslstained coronal sections from monkey AH4. From top to bottom, the sections are approximately $+17,+13,+8$, and $+4 \mathrm{~mm}$ from the interaural plane, respectively. Compare with Figures 2 and 6.

Scores on LL40 with reverse-order testing are shown in Table 3 and Figure 10. The data were averaged across eight successive 5 -min-delay intervals. A 2 (group) $\times 8$ (delay condition) repeated measures ANOVA again failed to reveal a difference between the groups $\left[F_{(1,6)}=0.30, p=0.60\right]$. Further, although there was an effect of delay $\left[F_{(7,42)}=27.29, p<0.001\right]$, there was no interaction between group and delay $\left[F_{(7,42)}=0.26, p=0.74\right]$. Thus, just as in the initial performance test, the monkeys performed more poorly at the longer delays, but those with the excitotoxic lesions of the amygdala and hippocampus were not worse than the controls. To determine whether there might have been transient disruptions of memory performance at long delays during the
$40 \mathrm{~d}$ test period, we also compared the groups on each of four $10 \mathrm{~d}$ blocks across the period. A 2 (group) $\times 4$ (block) repeated measures ANOVA revealed no significant main effects [group: $F_{(1,6)}=0.31, p=0.60$; block: $\left.F_{(3,18)}=0.08, p=0.97\right]$ and no group-by-block interaction $\left[F_{(3,18)}=0.17, p=0.92\right]$.

Finally, we examined the relationship between test scores at each stage and the degree of damage to each of the structures listed in Table 1. It is clear, first, that those monkeys with nearly complete loss of neurons in the amygdala (AH3, AH6), hippocampus ( $\mathrm{AH} 3, \mathrm{AH} 4)$, or both (AH3) did not perform any more poorly than the others in the group. Second, there were no negative correlations between the percentage of correct scores at 

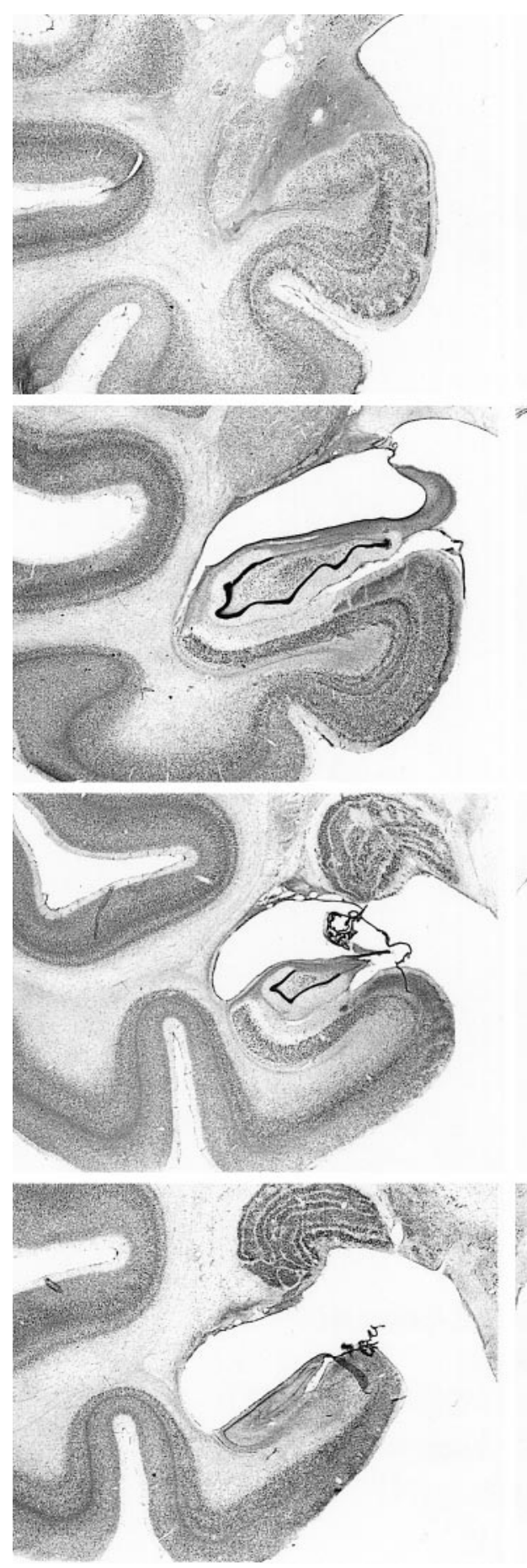
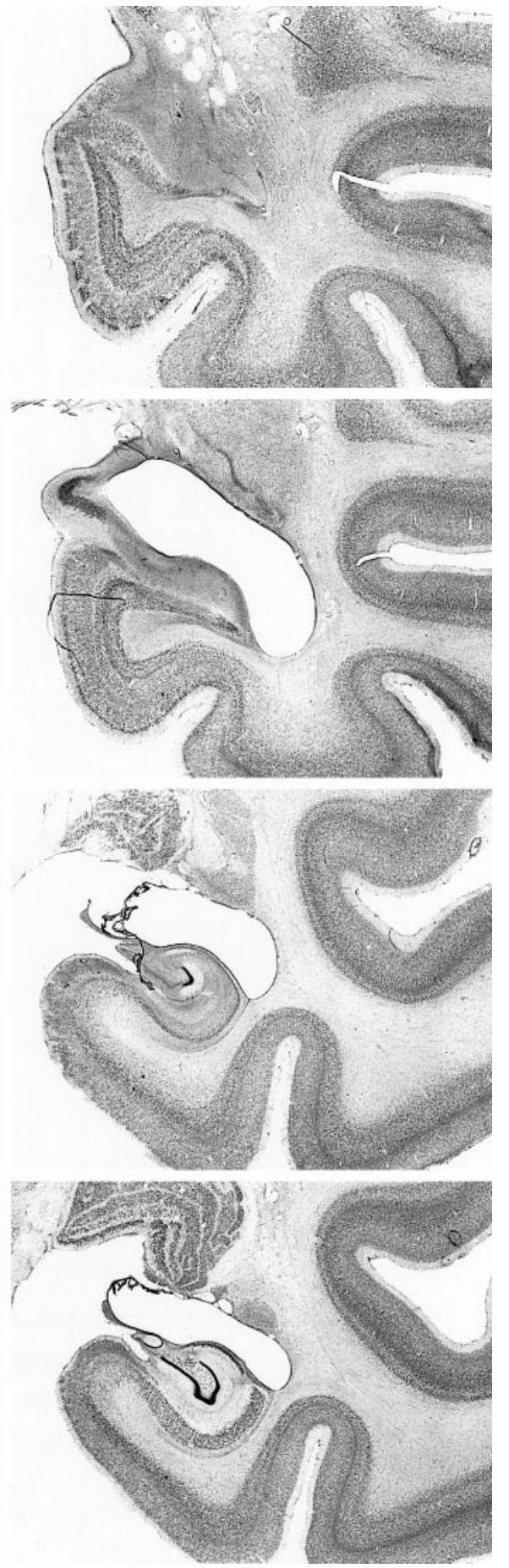

Figure 8. Photomicrographs of Nissl-stained coronal sections from monkey AH5. From top to bottom, the sections are approximately $+17,+13$, +8 , and $+4 \mathrm{~mm}$ from the interaural plane, respectively. Compare with Figures 2 and 6. any stage and the extent of damage to any structure. Indeed, the only correlations obtained were positive ones, namely, between percentage of damage to the hippocampus and mean percentage of correct responses on (1) the three longer delays of the initial performance test $\left(n=7, r_{s}=0.800, p<0.05\right)$ and (2) LL20 $(n=$ $\left.4, r_{s}=1.00, p<0.05\right)$, suggesting that, paradoxically, the greater the hippocampal damage, the better the recognition performance.

\section{Experiment 2}

The results (Table 4) failed to reveal group differences in either learning [Mann-Whitney $U$ test, trials: $U=7.5, p=0.59$; errors: $U=7.0, p=0.72]$ or on the performance test [2 (group) $\times 4$ (delay) repeated measures ANOVA; main effect for group, $F_{(1,5)}$ $=0.71, p=0.44]$. There was a significant effect of delay $\left[F_{(3,15)}=\right.$ $28.62, p<0.001]$ but no group-by-delay interaction $\left[F_{(3,15)}=0.81\right.$, $p=0.51]$. In addition, there was no group difference on the LL2 condition (Mann-Whitney $U$ test, $U=3.0, p=0.51$ ).

\section{DISCUSSION}

\section{Neural substrates of visual recognition}

The present findings indicate that extensive cell loss in the amygdala and hippocampus can leave DNMS performance unimpaired even when a $40 \mathrm{~min}$ period intervenes between sample and 


\begin{tabular}{|c|c|c|c|c|c|c|c|c|c|c|c|c|}
\hline \multirow[b]{2}{*}{ Case } & \multicolumn{2}{|c|}{ Preop } & \multicolumn{2}{|c|}{ Postop } & \multicolumn{4}{|c|}{$\underline{\text { Delays (sec) }}$} & \multicolumn{3}{|c|}{ List lengths } & \multirow[b]{2}{*}{ Avg } \\
\hline & $\mathrm{T}$ & $\mathrm{E}$ & $\mathrm{T}$ & $\mathrm{E}$ & 10 & 30 & 60 & 120 & 3 & 5 & 10 & \\
\hline $\mathrm{NC1}$ & 240 & 71 & 0 & 0 & 95 & 93 & 89 & 88 & 92 & 91 & 78 & 89.4 \\
\hline $\mathrm{NC} 2$ & 60 & 30 & 0 & 0 & 91 & 94 & 92 & 99 & 95 & 91 & 89 & 93.0 \\
\hline NC3 & 190 & 51 & 80 & 18 & 90 & 98 & 92 & 87 & 94 & 89 & 79 & 89.9 \\
\hline $\mathrm{NC4}$ & 60 & 19 & 0 & 0 & 94 & 93 & 90 & 90 & 87 & 79 & 74 & 86.7 \\
\hline Mean & 138 & 43 & 20 & 5 & 93 & 95 & 91 & 91 & 92 & 88 & 80 & 90.0 \\
\hline AH1 & 140 & 42 & 0 & 0 & 97 & 98 & 92 & 96 & 95 & 95 & 86 & 94.1 \\
\hline $\mathrm{AH} 2$ & 50 & 20 & 80 & 18 & 91 & 89 & 94 & 94 & 96 & 96 & 75 & 90.7 \\
\hline $\mathrm{AH} 3$ & 80 & 31 & 0 & 0 & 92 & 94 & 94 & 92 & 91 & 88 & 73 & 89.1 \\
\hline $\mathrm{AH} 4$ & 130 & 66 & 0 & 0 & 95 & 96 & 98 & 97 & 97 & 95 & 87 & 95.0 \\
\hline AH5 & 140 & 28 & 0 & 0 & 93 & 89 & 88 & 93 & 95 & 92 & 85 & 90.7 \\
\hline AH6 & 120 & 27 & 0 & 0 & 90 & 91 & 94 & 90 & 92 & 80 & 76 & 87.6 \\
\hline AH7 & 160 & 59 & 0 & 0 & 92 & 92 & 88 & 90 & 90 & 71 & 67 & 84.3 \\
\hline Mean & 117 & 39 & 11 & 3 & 93 & 93 & 93 & 93 & 94 & 88 & 78 & 90.3 \\
\hline
\end{tabular}

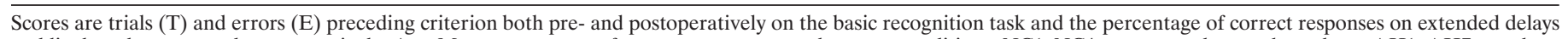

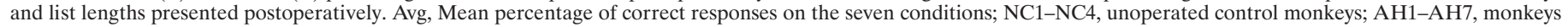
with bilateral excitotoxic lesions of the amygdala and hippocampus.

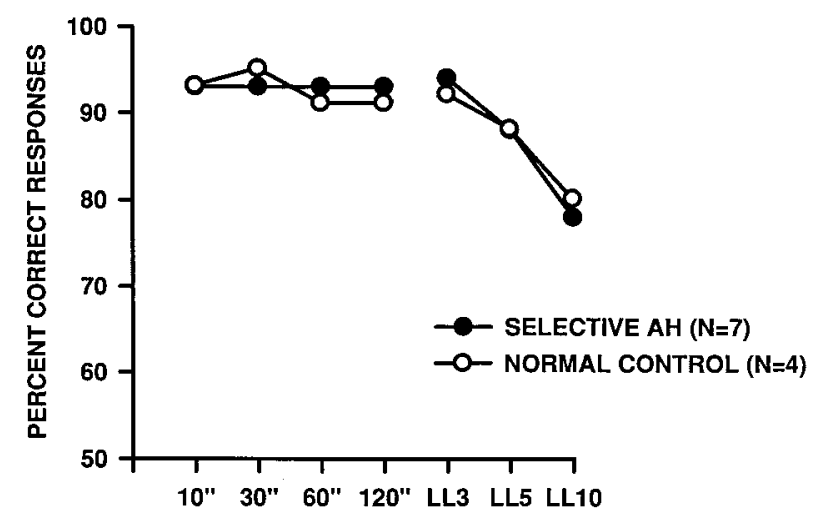

Figure 9. Group mean scores on the DNMS performance test. The curves on the left show the effects of imposition of increasingly longer delays between sample presentation and choice, whereas the curves on the right show the effects of list-length testing. For each list item the minimal delay is $20 \mathrm{sec} \times$ the length of the list. SELECTIVE $A H$, Monkeys with bilateral excitotoxic lesions of the amygdala and hippocampus; NORMAL CONTROL, unoperated control monkeys.

choice. Further, there was no evidence of an impairment even in those cases that had nearly complete cell loss in either or both of these structures. Taken together with our recent results regarding the behavioral effects of rhinal cortical lesions, the present data suggest that the visual recognition impairment originally observed after combined amygdala and hippocampal removals was attributable entirely to the concomitant damage to rhinal cortex (Fig. 11). In short, it now appears that, within the medial temporal lobe, the rhinal cortex is not only necessary but also sufficient to sustain visual recognition ability.

The critical role of the rhinal cortex in recognition memory was not easily anticipated from the initial set of findings. The medial temporal region of greatest importance for visual recognition has turned out to be the perirhinal cortex, with the entorhinal cortex appearing to play a subsidiary role (Horel et al., 1987; Meunier et al., 1993; Leonard et al., 1995). In the combined aspiration lesions of the amygdala and hippocampus, access to these structures was always gained by removing the underlying entorhinal cortex, in the course of which the perirhinal cortex also sustained partial unintended damage in some cases. However, as noted elsewhere (Murray, 1992), the inadvertent damage to the perirhinal cortex in the initial studies (Mishkin, 1978; Zola-Morgan et al., 1982; Murray and Mishkin, 1984; Saunders et al., 1984) was typically neither substantial nor bilaterally symmetrical. Therefore, direct damage to this cortical field could not account for the severe recognition impairment that consistently followed the combined amygdala and hippocampal ablations, and so there was little reason to suspect that this cortical field played a critical role in recognition memory.

Recently, however, it has become clear that combined amygdala and hippocampal ablations can interfere with perirhinal function in another way, namely, by disrupting perirhinal efferent fibers coursing through the aspirated tissue. Thus, ablation of the amygdala has been shown to transect anterior perirhinal (as well as entorhinal) fibers projecting through the ventral amygdalofugal pathway en route to at least one target structure, the magnocellular portion of the medial dorsal nucleus of the thalamus (Goulet et al., 1998). Furthermore, ablation of the hippocampal formation (i.e., Ammon's horn, dentate gyrus, and subicular complex) now is known to transect some posterior perirhinal (as well as entorhinal) efferents projecting through both the fimbria-fornix and posterior thalamic pathways en route to other medial thalamic structures, including the anterior and lateral dorsal nuclei (R. Saunders and D. Rosene, personal communication; J. Aggleton, M. Mishkin, and R. Saunders, personal communication). Consequently, it now appears that combined amygdala and hippocampal removals achieved by aspiration result in recognition failure, not because of damage to those structures but because of combined damage and disconnection of both the anterior and posterior portions of the perirhinal and entorhinal cortical fields. The same explanation presumably applies to the finding that greater impairment in visual recognition is produced by combined transections of the amygdalofugal pathways and fornix than by transection of either of these pathways alone (Bachevalier et al., 1985). Together, the results suggest that recognition memory is mediated by a cerebral circuit that includes both the rhinal cortex and the medial thalamus (Mishkin, 1982; Mishkin and Murray, 1994) as well as some other structures, such as the ventromedial frontal 
Table 3. DNMS with list length 40 and reverse-order testing

\begin{tabular}{|c|c|c|c|c|c|c|c|c|}
\hline \multirow[b]{2}{*}{ Case } & \multicolumn{8}{|c|}{ Delay in minutes } \\
\hline & 5 & 10 & 15 & 20 & 25 & 30 & 35 & 40 \\
\hline $\mathrm{NC1}$ & 83.5 & 74.5 & 66.5 & 66.5 & 54 & 59.5 & 61.5 & 55 \\
\hline $\mathrm{NC} 2$ & 96 & 84.5 & 81.5 & 76 & 75.5 & 65.5 & 61.5 & 52 \\
\hline $\mathrm{NC} 3$ & 91 & 78 & 80.5 & 79.5 & 65.5 & 68.5 & 68.5 & 70.5 \\
\hline $\mathrm{NC4}$ & 92.5 & 76.5 & 71.5 & 73.5 & 52 & 61 & 64.5 & 67.5 \\
\hline Mean & 90.7 & 78.4 & 75.0 & 73.9 & 61.7 & 63.6 & 64.0 & 61.2 \\
\hline $\mathrm{AH} 4$ & 86.5 & 80 & 74 & 74 & 68 & 59.5 & 59 & 53 \\
\hline AH5 & 97.5 & 79 & 78 & 77 & 69 & 73 & 63.5 & 62.5 \\
\hline AH6 & 87.5 & 71 & 66 & 70.5 & 51 & 62 & 65 & 71 \\
\hline AH7 & 82 & 68 & 70 & 60.5 & 63.5 & 60 & 59 & 60 \\
\hline Mean & 88.4 & 74.5 & 72.0 & 70.5 & 62.9 & 63.6 & 61.6 & 61.6 \\
\hline
\end{tabular}

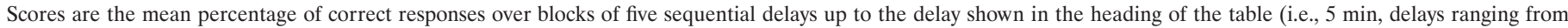

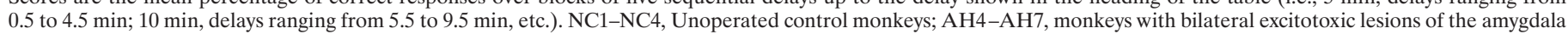
and hippocampus.

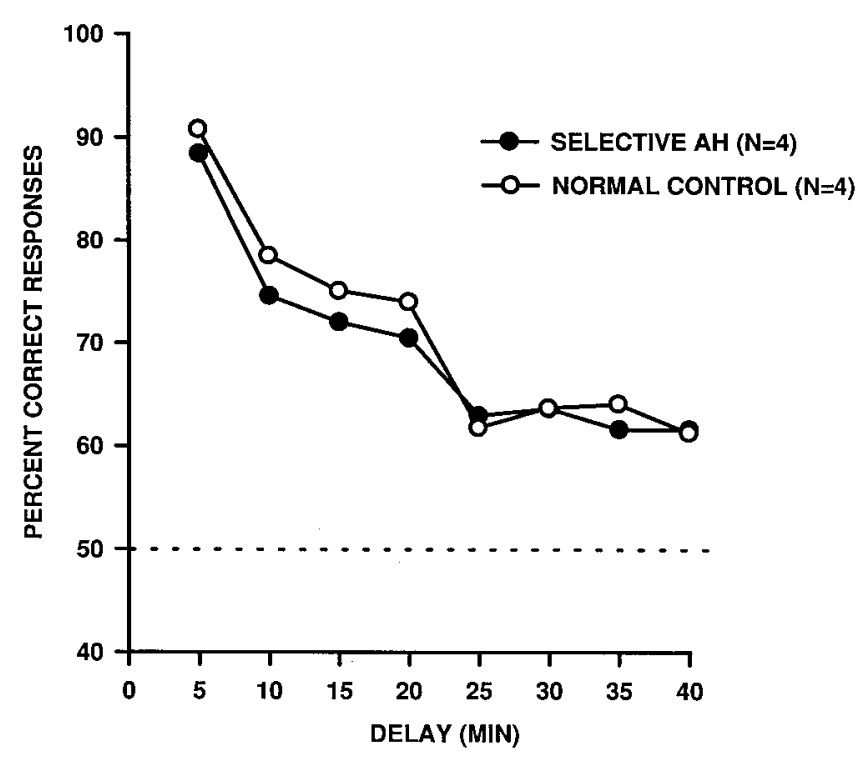

Figure 10. Group mean scores on DNMS administered with a list length of 40 and reverse-order testing. Each point represents the data obtained from a block of five sequential delays, the longest of which is shown on the abscissa. For example, the first point represents the mean score for delays ranging from 0.5 to $4.5 \mathrm{~min}$, the second point represents the mean score for delays ranging from 5.5 to $9.5 \mathrm{~min}$, etc. SELECTIVE $A H$, Monkeys with bilateral excitotoxic lesions of the amygdala and hippocampus; NORMAL CONTROL, unoperated control monkeys.

cortex (Bachevalier and Mishkin, 1986; Meunier et al., 1997), to which both of these regions project.

The results of our second assessment with DNMS differ from the results of Alvarez and colleagues (1995), who found that monkeys with hippocampal lesions were impaired significantly in DNMS when relatively long (10 and $40 \mathrm{~min}$ ) delays intervened between sample and choice. The discrepancy could be attributable to any or all of a number of factors that merit exploration. First, the monkeys in our study were trained on the DNMS rule preoperatively and then assessed on long delays postoperatively only after they had received $\sim 2$ months of testing with shorter delays; by contrast, the monkeys studied by Alvarez and colleagues were trained only postoperatively and previously had received only $\sim 1$ month of testing with short delays. Second, although both studies used DNMS, the details of the test proce- dures in the two studies differed. Thus, whereas we used lists of objects, Alvarez and colleagues examined memory for single items only. Also, whereas each of our sessions included delays that increased gradually from $<1$ to nearly $40 \mathrm{~min}$, each session in the study by Alvarez and colleagues included delays of a constant length. Finally, whereas our monkeys always remained in the test apparatus during the delay interval between sample and choice, the monkeys studied by Alvarez and colleagues (1995) were removed from the test apparatus for the trials with long delays (on which their hippocampectomized monkeys were impaired), but not for trials with short delays (on which their hippocampectomized monkeys were unimpaired). As has been suggested elsewhere (Nadel, 1995), it is possible that the different treatment for the different delay conditions is the source of the impairment in their hippocampectomized monkeys.

A third major difference between the two studies concerns the method of producing the lesion. Whereas we used an excitotoxin, Alvarez and colleagues (1995) used radiofrequency. In view of the anatomical findings described above, it seems possible that radiofrequency lesions disrupt rhinal cortical efferents coursing through the subiculum en route to the thalamus and that this amount of damage to the rhinal corticothalamic circuit (and perhaps rhinal corticofrontal circuits as well) is sufficient to produce a recognition deficit at long, but not at short, delays.

\section{Neural substrates of location memory}

Extensive cell loss in the amygdala and hippocampus also failed to yield an impairment on the delayed nonmatching-to-position task. Given the wealth of information concerning the contribution of the hippocampus to spatial memory in rodents (O'Keefe and Nadel, 1978; Morris et al., 1982; Jarrard, 1993; Eichenbaum et al., 1994), it has commonly been assumed that spatial memory in monkeys likewise depends specifically on the hippocampus (Mahut and Moss, 1986; Parkinson et al., 1988; Angeli et al., 1993; Malkova et al., 1995). In all of the foregoing studies in monkeys, however, the removals included not only the hippocampus but also the subicular complex and the parahippocampal cortex (areas TF and TH), either or both of which could well have contributed to the spatial memory impairments. Recently, two lines of evidence have emerged in support of a dissociation of hippocampal and parahippocampal contributions to different aspects of spatial memory. First, recent functional imaging studies suggest a role for the parahippocampal cortex in topographic spatial orientation 


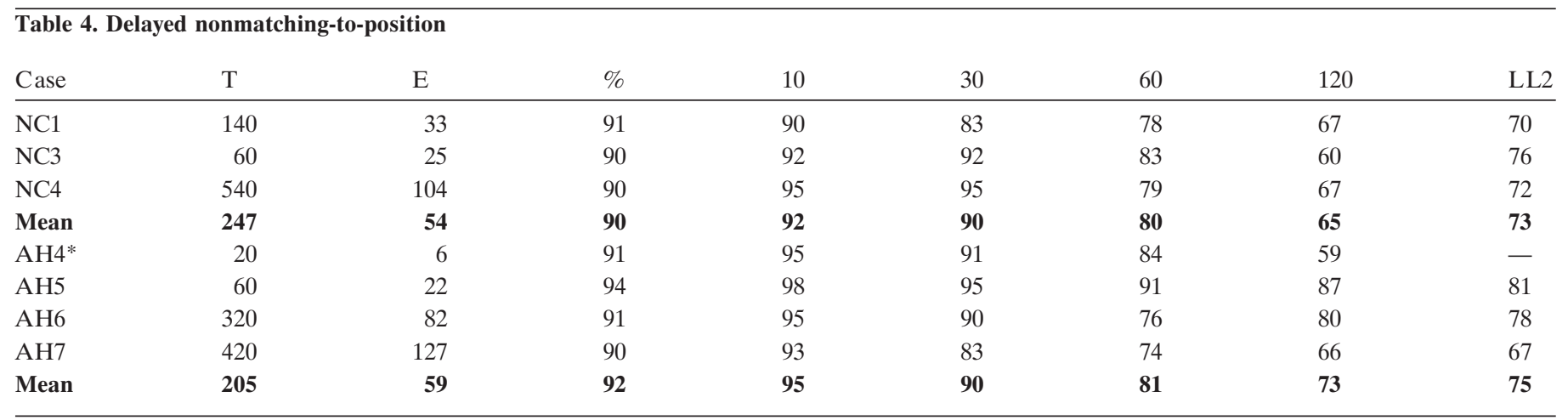

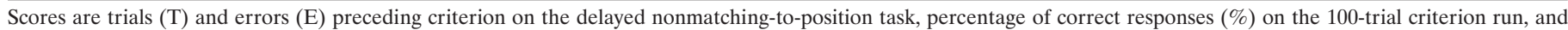

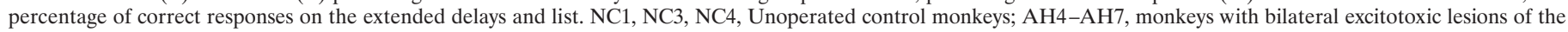
amygdala and hippocampus. *AH4 was unavailable for testing on the list length 2 (LL2) condition.

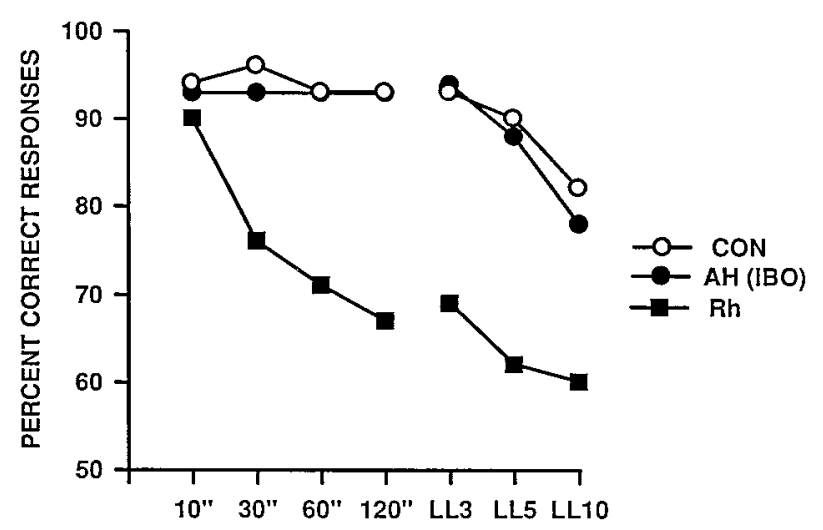

Figure 11. Comparison between the results for monkeys with AH lesions (present study) and those for identically trained monkeys with rhinal cortex lesions reported by Meunier et al. (1993). $A H(I B O)$, Monkeys with bilateral excitotoxic lesions of the amygdala and hippocampus $(n=7) ; R h$, monkeys with bilateral removals of the rhinal cortex $(n=7)$; CON, unoperated control monkeys $(n=8)$, consisting of the four controls from the present study plus the four controls from Meunier et al. (1993).

(Aguirre et al., 1996; Maguire et al., 1996; Aguirre and D'Esposito, 1997), a role that may reflect parahippocampal processing of the geometry of local space (Epstein and Kanwisher, 1998). Second, recent work in rodents (McNaughton et al., 1996; Whishaw et al., 1997) has suggested that the hippocampus may be more important for path integration on the basis of self-motion cues than for location memory, per se. Both of these suggestions are consistent with the negative result we obtained in Experiment 2 and with the positive result obtained after excitotoxic hippocampal lesions in another recent study in which monkeys were required to learn where to reach within two-dimensional spatial scenes (Murray et al., 1998). Because there is evidence for a hippocampal contribution as well as a parahippocampal contribution to spatial navigation (Maguire et al., 1997), the dissociation outlined above is by no means complete. In future studies the two functions that often are confounded in tests of spatial memory, namely, memory for the spatial layout of a map and memory for movement within the map, will need to be assessed separately.

\section{REFERENCES}

Aggleton JP, Burton MJ, Passingham RE (1980) Cortical and subcortical afferents to the amygdala of the rhesus monkey (Macaca mulatta). Brain Res 36:243-248.

Aguirre GK, D'Esposito M (1997) Environmental knowledge is sub- served by separable dorsal/ventral neural areas. J Neurosci 17:2512-2518.

Aguirre GK, Detre JA, Alsop DC, D’Esposito M (1996) The parahippocampus subserves topographic learning in man. Cereb Cortex 6:823-829.

Alvarez P, Zola-Morgan S, Squire LR (1995) Damage limited to the hippocampal region produces long-lasting memory impairment in monkeys. J Neurosci 15:3796-3807.

Angeli SJ, Murray EA, Mishkin M (1993) Hippocampectomized monkeys can remember one place but not two. Neuropsychologia 31:1021-1030.

Bachevalier J, Mishkin M (1986) Visual recognition impairment follows ventromedial but not dorsolateral prefrontal lesions in monkeys. Behav Brain Res 20:249-261.

Bachevalier J, Parkinson JK, Mishkin M (1985) Visual recognition in monkeys: effects of separate vs. combined transection of fornix and amygdalof ugal pathways. Exp Brain Res 57:554-561.

Eacott MJ, Gaffan D, Murray EA (1994) Preserved recognition memory for small sets, and impaired stimulus identification for large sets, following rhinal cortex ablations in monkeys. Eur $\mathrm{J}$ Neurosci 6:1466-1478.

Eichenbaum H, Otto T, Cohen NJ (1994) Two functional components of the hippocampal memory system. Behav Brain Sci 17:449-518.

Epstein R, Kanwisher N (1998) A cortical representation of the local visual environment. Nature 392:598-601.

Goulet S, Doré FY, Murray EA (1998) Aspiration lesions of the amygdala disrupt the rhinal corticothalamic projection system in rhesus monkeys. Exp Brain Res 119:131-140.

Herzog AG, Van Hoesen GW (1976) Temporal neocortical afferent connections to the amygdala in the rhesus monkey. Brain Res 115:57-69.

Horel JA, Pytko-Joiner DE, Voytko ML, Salsbury K (1987) The performance of visual tasks while segments of the inferotemporal cortex are suppressed by cold. Behav Brain Res 23:29-42.

Jarrard LE (1993) On the role of the hippocampus in learning and memory in the rat. Behav Neural Biol 60:9-26.

Leonard BW, Amaral DG, Squire LR, Zola-Morgan S (1995) Transient memory impairment in monkeys with bilateral lesions of the entorhinal cortex. J Neurosci 15:5637-5659.

Maguire EA, Frackowiak RSJ, Frith CD (1996) Learning to find your way - a role for the human hippocampal formation. Proc R Soc Lond [Biol] 263:1745-1750.

Maguire EA, Frackowiak RSJ, Frith CD (1997) Recalling routes around London: activation of the right hippocampus in taxi drivers. J Neurosci 17:7103-7110.

Mahut H, Moss M (1986) The monkey and the sea horse. In: The hippocampus (Isaacson RL, Pribram KH, eds), pp 241-279. New York: Plenum.

Malkova L, Mishkin M, Bachevalier J (1995) Long-term effects of selective neonatal temporal lobe lesions on learning and memory in monkeys. Behav Neurosci 109:212-226.

Malkova L, Gaffan D, Murray EA (1997) Excitotoxic lesions of the amygdala fail to produce impairment in visual learning for auditory secondary reinforcement but interfere with reinforcer devaluation effects in rhesus monkeys. J Neurosci 17:6011-6020. 
McNaughton BL, Barnes CA, Gerrard JL, Gothard K, Jung MW, Knierim JJ, Kudrimoti H, Qin Y, Skaggs WE, Suster M, Weaver KL (1996) Deciphering the hippocampal polyglot: the hippocampus as a path integration system. J Exp Biol 199:173-185.

Meunier M, Bachevalier J, Mishkin M, Murray EA (1993) Effects on visual recognition of combined and separate ablations of the entorhinal and perirhinal cortex in rhesus monkeys. J Neurosci 13:5418-5432.

Meunier M, Bachevalier J, Mishkin M (1997) Effects of orbital frontal and anterior cingulate lesions on object and spatial memory in rhesus monkeys. Neuropsychologia 35:999-1015.

Mishkin M (1978) Memory in monkeys severely impaired by combined but not by separate removal of amygdala and hippocampus. Nature 273:297-298.

Mishkin M (1982) A memory system in the monkey. Philos Trans R Soc Lond [Biol] 298:83-95.

Mishkin M, Murray EA (1994) Stimulus recognition. Curr Opin Neurobiol 4:200-206.

Morris RGM, Garrud P, Rawlins JNP, O’Keefe J (1982) Place navigation impaired in rats with hippocampal lesions. Nature 297:681-683.

Murray EA (1992) Medial temporal lobe structures contributing to recognition memory: the amygdaloid complex versus the rhinal cortex. In: The amygdala: neurobiological aspects of emotion, memory, and mental dysfunction (Aggleton JP, ed), pp 453-470. New York: Wiley-Liss.

Murray EA, Mishkin M (1984) Severe tactual as well as visual memory deficits follow combined removal of the amygdala and hippocampus in monkeys. J Neurosci 4:2565-2580.

Murray EA, Mishkin M (1996) 40 minute visual recognition memory in rhesus monkeys with hippocampal lesions. Soc Neurosci Abstr 22:281.

Murray EA, Gaffan EA, Flint Jr RW (1996) Anterior rhinal cortex and amygdala: dissociation of their contributions to memory and food preference in rhesus monkeys. Behav Neurosci 10:30-42.

Murray EA, Baxter MG, Gaffan D (1998) Monkeys with rhinal cortex damage or neurotoxic hippocampal lesions are impaired on spatial scene learning and object reversals. Behav Neurosci, in press.

Nadel L (1995) The role of the hippocampus in declarative memory: a comment on Zola-Morgan, Squire, and Ramus (1994). Hippocampus $5: 232-234$

O’Boyle Jr VJ, Murray EA, Mishkin M (1993) Effects of excitotoxic amygdalo-hippocampal lesions on visual recognition in rhesus monkeys. Soc Neurosci Abstr 19:438.

O'Keefe J, Nadel L (1978) The hippocampus as a cognitive map. Oxford: Clarendon.
Parkinson JK, Murray EA, Mishkin M (1988) A selective mnemonic role for the hippocampus in monkeys: memory for the location of objects. J Neurosci 8:4159-4167.

Saunders RC, Rosene DL (1988) A comparison of the efferents of the amygdala and the hippocampal formation in the rhesus monkey. I. Convergence in the entorhinal, prorhinal, and perirhinal cortices. J Comp Neurol 271:153-184.

Saunders RC, Murray EA, Mishkin M (1984) Further evidence that amygdala and hippocampus contribute equally to recognition memory. Neuropsychologia 22:785-796.

Saunders RC, Aigner TG, Frank JA (1990) Magnetic resonance imaging of the rhesus monkey brain: use for stereotactic neurosurgery. Exp Brain Res 81:443-446.

Stefanacci L, Suzuki WA, Amaral DG (1996) Organization of connections between the amygdaloid complex and the perirhinal and parahippocampal cortices in macaque monkeys. J Comp Neurol 375:552-582.

Suzuki WA, Amaral DG (1990) Cortical inputs to the CA1 field of the monkey hippocampus originate from the perirhinal and parahippocampal cortex but not from area TE. Neurosci Lett 115:43-48.

Suzuki WA, Zola-Morgan S, Squire LR, Amaral DG (1993) Lesions of the perirhinal and parahippocampal cortices in the monkey produce long-lasting memory impairment in the visual and tactual modalities. J Neurosci 13:2430-2451.

Van Hoesen GW (1981) The differential distribution, diversity and sprouting of cortical projections to the amygdala in the rhesus monkey. In: The amygdaloid complex (Ben-Ari Y, ed), pp 77-90. Amsterdam: Elsevier North-Holland.

Van Hoesen GW, Pandya DN (1975) Some connections of the entorhinal (area 28) and perirhinal (area 35) cortices of the rhesus monkey. I. Temporal lobe afferents. Brain Res 95:1-24.

Whishaw IQ, McKenna JE, Maaswinkel H (1997) Hippocampal lesions and path integration. Curr Opin Neurobiol 7:228-234.

Witter MP, Van Hoesen GW, Amaral DG (1989) Topographical organization of the entorhinal projection to the dentate gyrus of the monkey. J Neurosci 9:216-228.

Zola-Morgan S, Squire LR, Mishkin M (1982) The neuroanatomy of amnesia: amygdala-hippocampus versus temporal stem. Science 218:1337-1339.

Zola-Morgan S, Squire LR, Amaral DG, Suzuki WA (1989) Lesions of perirhinal and parahippocampal cortex that spare the amygdala and hippocampal formation produce severe memory impairment. J Neurosci 9:4355-4370. 